powerful conflict of interest inherent in scientific refereeing, as a referee's own work is often the target of an author's article.

We scientists owe it to ourselves and to our financial patrons to be more open and equitable in the critical assessments of non-consensual views and results. Should we perhaps consider a system of completely open refereeing in which the author is allowed to publish his article together with the signed reports of the referees (if the latter are critical) if he so wished? There would still be some people who might publish and risk their reputations despite the openly stated criticism of experts. This can, however, do no harm in the long run as only truly invariant results and concepts would stand up to the relentless scrutiny by many independent researchers. Popperian falsification tests would consign the failures to the scrap heap anyway.

A. Thyagaraja

9 Medlicott Drive,

Abingdon, Oxfordshire, OXI4 5PS, UK

\section{Ethical bounds}

SIR-In a recent issue (Nature 334, 560; 1988), members of the Department of Cell Biology of the Max Planck Institute in Göttingen express the opinion that our study on the activation of the human embryonic genome (Nature 332, 459-461; 1988) "oversteps the ethical bounds of scientific work". They also propose a moratorium on work on human preembryos until ethical boundaries have been established.

In the United Kingdom, ethical boundaries for work on human pre-embryos and a regulating authority to supervise them were established in $1985^{\prime}$. A proposal for the research work reported by us was submitted to this licensing authority and was approved and funded by the Medical Research Council of Great Britain. These circumstances were acknowledged at the end of our letter.

We have each considered the ethical issues raised by our work carefully over many years, and after discussions with theologians, lawyers and philosophers not only believe this work to be ethical but, in common with many respected scientists in this country ${ }^{2}$, believe that limited and controlled systematic research is needed and should be encouraged.

Peter Braude

VIRGINIA BOLTON STEPHEN MOORE

Embryo and Genetic Research Group,

Department of Obstetrics and

Gynaecology and

Department of Anatomy,

The University,

Cambridge, UK

1. First Report of the Voluntary Licensing Authority for Human In Vitro Fertilization and Embryology (1986)

2. Human Embryo Research - Yes or No? (eds Bock, G. \& O'Conner, M.) (Ciba Foundation, London, 1986).

\section{Outlandish claims}

SIR-It would be a pity if a journal such as. Nature could not find time and space for a serious appraisal of such claims as those of Benveniste and his colleagues (Nature 333, 816-818; 1988). But, in my opinion, it is absolutely essential that in the first instance outlandish claims should be assessed critically by means of the most scientifically valid and relevant laboratory approaches available in that field at that time.

Let me give you an example, also from the allergy field, of which I have personal experience and which (needless to say) is frequently subject to such claims. A few years ago a reporter from the local paper (The Birmingham Post) sought my opinion about a story that he had picked up in Malvern, that hay-fever sufferers there were being cured by eating beeswax capping obtained from a local bee-keeper. It seemed to me just possible that such people were imbibing small amounts of pollen products within the beeswax, and this was leading to their auto-desensitization. But the problem with this explanation was that their hay fever was caused by hypersensitivity to common grass and tree pollens, whereas the bees were collecting flower pollen. Nevertheless, we set up a small pilot study in our laboratory to explore this possibility, involving the monitoring of levels of antibody (sensitizing and protecting) in the allergic individuals' circulation in relation to any change in their clinical status. This preliminary study led to a full-scale 'doubleblind' investigation of the similarly claimed efficacy of pollen B tablets (available over the counter from healthfood shops and chemists) in the treatment of hay fever.

In neither study did we find any experimental evidence, based on our current understanding of the mechanism underlying the immunopathology of allergic responses of the hay-fever type, to suggest that such forms of self-treatment were having any beneficial organic effect. But we had at least made the effort to investigate the claims in a rational scientific manner. Similarly, it would be possible to appraise, for example, the extravagant claims of certain clinical ecologists that over 90 per cent of cases of rheumatoid arthritis are attributable to a food allergy, because a whole battery of laboratory methods of assessing the onset and progression of this disease are now readily available.

Turning to the surprising claims of Benveniste and his colleagues, surely here too it is first necessary to assess them by the most reliable and relevant laboratory procedures currently available in this area. This means that, for a start, one would choose the mast cell rather than the basophil as the effector cell in question because mast cells can be obtained in highly pure form in high yield, and one would therefore expect much less interexperimental variation. Furthermore, one would measure the release of histamine (or some other mediator), while at the same time measuring the release of a cytoplasmic marker enzyme such as LDH, to ensure that the effect observed was non-cytolytic and therefore really attributable to the immunological triggering of the effector cell and not due to some artefact, rather than continue to struggle with the attempted measurement of the notoriously unreliable degranulation endpoint.

It is because this technique is so unreliable that the so-called new microscopic test for detecting allergies of the hay fever/asthma type based on this principle (reported by Shelley and Juhlin in Nature 191, 1056; 1961) never caught on in routine clinical immunology laboratories. Despite this, Benveniste has persisted in developing a more elaborate assay kit which, in the experience of those of us who have had the opportunity to assess it critically, appears to suffer from many of the experimental shortcomings of the attempted accurate quantitation of basophil degranulation referred to in the report that followed your recent visit to Benveniste's laboratory. The explanations for this experimental variation are manifold: basophils are extremely fragile cells, readily degranulated by nonspecific stimuli; they are present as only a minor population of peripheral blood leukocytes; the amount of IgE antibody bound to their $\mathrm{Fc}$ receptors differs from individual to individual, and so forth.

University of Birmingham,

D. R. STANWORTH

Rheumatology and Allergy Research Unit, Department of Immunology,

Medical School, Vincent Drive,

Birmingham B15 2TJ, UK

SIR-While I am highly sceptical of the claims made in the article by Benveniste and his colleagues, the work was nonetheless appropriately conducted with seemingly reasonable controls and reported in scientific fashion. There may well have been errors in methods and/or interpretation as regards the effectiveness of their dispersion procedures, but the scientific community has well-tested standard methods for investigating such claims. These methods do not require the use of journalists or magicians and their inclusion on an investigating team is demeaning to the scientific process. It is also highly unusual to include a specialist in 'misconduct in science' when there have been no allegations of such.

MARK JoHnSON

Massachusetts Institute of Technology,

Rm 3-160

77 Massachusetts Avenue,

Cambridge, Massachusetts 02139, USA 